\title{
DORMIR Y DESPERTAR: UN ACERCAMIENTO FENOMENOLÓGICO A LA IPSEIDAD ZAMBRANIANA \\ Gabriel Astey*
}

RESUMEN: En la antropología filosófica de María Zambrano, dormir y despertar no son meros actos empíricos del vivir cotidiano, sino operaciones egológicas formales involucradas en el proceso de autoconstitución del sujeto. En este artículo se describen poniendo en diálogo el libro zambraniano Los sueños y el tiempo con la noción de ipseidad, tal como la entienden Paul Ricoeur, Edmund Husserl, Hans Blumenberg y Michel Henry.

\section{yose \\ SLEEPING AND AWAKENING: \\ A PHENOMENOLOGICAL APPROACH TO ZAMBRANO'S SELFHOOD}

ABSTRACT: In Maria Zambrano's philosophical anthropology, sleeping and awakening are not mere empirical acts of daily life, but formal egological acts involved in self-construction. In this article, we will discuss Maria Zambrano's work, The dreams and time, along with the idea of selfhood as understood by Paul Ricoeur, Edmund Husserl, Hans Blumenberg, and Michel Henry.

PALABRAS CLAVE: María Zambrano, dormir, vigilia, ipseidad, distancia fenomenológica. KEY WORDS: Maria Zambrano, sleeping, vigil, selfhood, phenomenological distance.

RECEPCIÓN: 23 de septiembre de 2014.

APROBACIÓN: 26 de septiembre de 2015.

* Instituto Superior de Intérpretes y Traductores. 
CITAM Derechos Reservados.

La reproducción total o parcial de este artículo se podrá hacer si el ITAM otorga la autorización previamente por escrito. 


\section{DORMIR Y DESPERTAR: \\ UN ACERCAMIENTO \\ FENOMENOLÓGICO A LA \\ IPSEIDAD ZAMBRANIANA}

\section{La ipseidad en el pensamiento de María Zambrano}

Distingue Paul Ricoeur en Sí mismo como otro (1990) una "identidad-idem" de una "identidad-ipse". Caracterizan a la primera: a) la unicidad numérica — “de dos veces que ocurre una cosa designada por un nombre invariable en el lenguaje ordinario, decimos que no constituyen dos cosas diferentes sino 'una sola y misma cosa"”_-; b) la semejanza extrema — “decimos de X y de Y que llevan el mismo traje, es decir, atuendos tan similares que resulta indiferente intercambiarlos" - ; ${ }^{2}$ c) la continuidad ininterrumpida a lo largo del tiempo "entre el primero y el último estadio del desarrollo de lo que consideramos el mismo individuo; este criterio prevalece en todos los casos en que el crecimiento, el envejecimiento, actúan como factores de desemejanza". ${ }^{3}$ Compendiadas y referidas a la identidad de las personas, las tres notas conforman el carácter, esto es, "el conjunto de los signos distintivos que permiten identificar de nuevo a un individuo humano como siendo el mismo. [El carácter] acumula la identidad numérica y cualitativa, la continuidad ininterrumpida y la permanencia en el tiempo". ${ }^{4}$ Contrasta con esta noción

${ }^{1}$ Paul Ricoeur, Sí mismo como otro, 2006, México, Siglo XXI, p. 110.

${ }^{2}$ Loc. cit.

${ }^{3}$ Ibid., p. 111.

${ }^{4}$ Ibid., p. 113. 
"fuerte" de identidad-idem la identidad-ipse, una modalidad de permanencia en el tiempo fundada en el "mantenimiento de sí", en la capacidad de las personas de establecer compromisos a través de la distancia temporal: "La palabra mantenida expresa un mantenerse a sí que no se deja inscribir, como el carácter, en la dimensión de algo en general, sino, únicamente, en la del ¿quién? [...] Una cosa es la continuación del carácter; otra, la constancia en la amistad". ${ }^{5}$

Ahora bien, aunque Ricoeur circunscriba en ese libro la ipseidad al campo de la ética intersubjetiva, ello no impide notar que la facultad compromisoria característica de la identidad-ipse presupone en quien da su palabra cierta continuidad ininterrumpida, característica de la identidad-idem; en efecto, la palabra dada se mantiene a pesar de las transformaciones dóxicas y volitivas ocurridas en el paso del individuo a través del tiempo y en el ámbito del "mundo de la vida" (Lebenswelt): una persona amnésica o trastornada, incapaz de reconocerse como la misma que se comprometió, no puede cumplir una promesa. En consideración de estos requisitos, se puede pensar también el concepto de identidad-ipse fuera del campo de la ética intersubjetiva y en el de una egología más restringida. Así lo hizo el propio Ricoeur en Freud: una interpretación de la cultura (1965), donde la tensión entre la unicidad del sujeto y la desemejanza que lo amenaza - ocurrida por obra de los cambios que el individuo sufre a lo largo del tiempo - se manifiesta en la figura de un cogito dislocado, de una apercepción diferida:

Reflexión no es intuición o, dicho en términos positivos: la reflexión es el esfuerzo por captar al Ego del Ego Cogito en el espejo de sus objetos, de sus obras y, finalmente, de sus actos. [...] ¿Por qué la posición del Ego debe volver a ser captada a través de sus actos? Precisamente porque no está dada ni en una evidencia psicológica ni en una intuición intelectual ni en una visión mística [...] La primera verdad — existo, piensoqueda tan vacía como irrebatible. Debe ser "mediatizada" por las representaciones, acciones, obras, instituciones y monumentos que la objetivan; es en esos objetos, en el sentido más amplio del término, donde el Ego debe perderse y encontrarse. ${ }^{6}$

${ }^{5}$ Ibid., p. 118.

${ }^{6}$ Paul Ricoeur, Freud: una interpretación de la cultura, 1990, México, Siglo XXI, p. 41. 
Con el propósito de bosquejar en este artículo un perfil de la subjetividad en la antropología filosófica de María Zambrano, ${ }^{7}$ tomo en préstamo el concepto ricoeuriano de ipseidad aunque desplazando el foco de interés de la noción del ámbito de la ética interpersonal al de la constitución formal del yo. Sostengo entonces, tanto con Ricoeur como con Husserl, que la identidad-ipse implica la disociación del sujeto en un ego noético relativamente estable y un ego noemático multiplicado en una diversidad de vivencias que proveen al noético contenidos "biográficos" concretos a medida que la bina que forman juntos preside el tránsito existencial del individuo en el que están encarnados. En el caso de la egología zambraniana son dos, por lo menos, los factores que ponen en entredicho la continuidad de la persona en el tiempo: la incapacidad de la conciencia de alcanzar un estado atencional completo, una vigilia total, y la imposibilidad de esa conciencia de mantenerse siempre despierta: como se verá, la forzosidad del dormir compromete al sujeto zambraniano a una tarea intermitente y vitalicia de reconstrucción de sus facultades intelectivas, de reconstitución de sí mismo.

En esta filosofía, el concepto de sujeto no es, entonces, de contextura monolítica ni tampoco resulta de un acto de apercepción intelectual a priori. Admito que, en el marco de la subjetividad zambraniana, existe en efecto una forma de apercepción inmediata interna, la del yo en la psique encarnada y dormida, pero la conformación cabal del sujeto no se realiza de ese modo, sino que ahí más bien comienza un desarrollo que conduce al surgimiento simultáneo de la conciencia y el estado de vigilia, y que nunca culmina del todo, pues devenir-persona es tarea permanente del individuo. Más que de una autodonación plena, de lo que se trata en el pensamiento de la andaluza es de un proceso de constitución del sujeto a partir de un embrión anímico. En este orden de ideas,

${ }^{7}$ Desde la primera monografía sobre la autora — Juan Fernando Ortega Muñoz, Introducción al pensamiento de María Zambrano, 1994, México, FCE- hasta la más autorizada de las recientes - Jesús Moreno Sanz, El logos oscuro: Tragedia, mística y filosofía en María Zambrano, 4 vols., 2008, Madrid, Verbum - la crítica especializada es unánime al señalar que lo esencial de esa antropología está expresado en las dos obras de Zambrano sobre el onirismo: El sueño creador (1965) y Los sueños y el tiempo (1992), libro este último sobre el que baso los análisis del presente ensayo, en la medida en que es más rico en descripciones fenomenológicas de la constitución de la subjetividad que el de 1965 . 
Los sueños y el tiempo no es solamente un ensayo de fenomenología "del sujeto privado de tiempo", ${ }^{8}$ sino también un ejercicio de fenomenología genética de la subjetividad, un intento de explicar la manera en que la conciencia humana está fundada en un subsuelo psíquico que, a su vez, está fundado en el soporte de la carne; como dice la autora, se trata de reconocer que: "si la vida es sueño, es sueño que pide despertar. Enajenación inicial de alguien que busca identificarse [...] Pues que el sueño pide realidad. Y el que sueña pide salir de ese estado en que, desgraciado o feliz, yace como larva en su capullo".9

En el ámbito de esta génesis del ego la noción de ipseidad se revela oportuna: si bien en su fondo último la subjetividad zambraniana ostenta, como diría Ricoeur, una identidad-idem, esto es, una identidad sin fisura ni distancia de sí misma, e inmune a las vicisitudes de la temporalidad, éste es apenas el punto de arranque de un trabajo de conformación de una identidad-ipse, escindida en una psique matriz y una conciencia emergente, y sometida a las exigencias de los diversos órdenes temporales que rigen la economía existencial del sujeto. Se trata de una ipseidad difícil de articular y de mantener:

Jamás el alguien humano se ofrece visible en una total presencia. Ninguna claridad conocida lo baña por entero. Y una resistencia invencible lo retiene dentro: dentro de sí mismo, mirado desde otro; más allá de sí, sentido desde sí mismo [...] Su presencia es aparición, fenómeno, aun para sí mismo [...] Parece emerger de un remoto allá: estar viniendo, apareciéndose como si naciera, como si fuera a nacer del todo: deteniéndose y aun volviendo cuando parece va a lograrlo. Retenido en un lugar invisible sin darse del todo a luz: sin actualizarse nunca del todo. ${ }^{10}$

Identificación procesual, ontogénesis conflictiva, el tópico de "tratar de nacer del todo" se formula también en la antropología zambraniana como "padecimiento de la propia trascendencia":

El hacer aparecer la realidad que le rodea es una función del ser hombre, la específica a lo que sabemos. Mas esa función es el cumplimiento de

${ }^{8}$ María Zambrano, Los sueños y el tiempo, 1992, Madrid, Siruela, p. 19.

${ }^{9}$ Ibid., p. 16.

${ }^{10}$ Ibid., p. 37. 
otra que la sostiene y subsiste bajo ella: el padecerla. Y el serla. El tratar con la realidad humanamente es padecer sus ocultaciones. $\mathrm{Y}$ en cuanto a la "realidad" que es el hombre, el padecerla y padecerse en ella y desde ella — desde lo que ocultamente padece - es lo que se le revela - la realidad objetiva- y lo que de sí mismo se actualiza y trasciende. ${ }^{11}$

En efecto, las ideas de pasividad inmanente y actividad trascendente son las más comprehensivas para llevar a buen destino el trabajo de entender el modo en que la estructura de la temporalidad y la actividad onírica de la persona zambraniana se entrelazan en aras de articular la ipseidad. ${ }^{12}$

Mi acercamiento a Los sueños y el tiempo es deliberadamente parcial y oblicuo. Lo primero, por necesidad: describir en detalle la interacción de todos los elementos de la forma-sueño, ${ }^{13}$ de sus modos temporales y sus operaciones anímicas, el carácter económico-pulsional de las mismas, el proyecto existencial de devenir-persona en que la formasueño está comprometida, todo eso rinde para escribir un libro. En cuanto a lo segundo: ante una literatura especializada repleta de glosas congeniales, ${ }^{14}$ encuentro más productivo para interpretar la filosofía zambraniana del soñar y los sueños dejar hablar a Husserl —y, en menor

${ }^{11}$ Ibid., p. 42.

${ }^{12}$ En la egología zambraniana - cuya descripción exhaustiva excede los límites de este texto- - el sujeto ejecuta diversas operaciones anímicas e intelectuales en el contexto de tres modos temporales: la sucesión, la duración y la atemporalidad. La sucesión es la forma temporal de la vigilia; la duración, la del dormir puro (es decir, no onírico); la atemporalidad, la del soñar. En estas páginas me ocupo solo del dormir y el despertar.

${ }^{13}$ Muy brevemente: entiendo la forma-sueño como una sinécdoque particularizante de la subjetividad zambraniana, una instancia dinámica que representa a escala las vicisitudes de la vida humana porque vincula los componentes de la persona (la psique y la conciencia) con los modos del tiempo (duración, sucesión y atemporalidad) según los regímenes noéticos del sujeto (dormir, soñar, velar) en aras de que este alcance su meta existencial: la autognosis.

${ }^{14}$ Más de una década después de emitido sigue vigente el diagnóstico de Ana Bundgård sobre las prácticas de los exégetas confrontados con la obra de vejez de María Zambrano, como Claros del bosque (1977) o Los sueños y el tiempo: "la ausencia de unidad interna que caracteriza los fragmentos [...] las contradicciones derivadas de la yuxtaposición de ensayos que, escritos en distintas etapas de la vida y pensamiento de la autora, han sido ensamblados posteriormente, todo ello dificulta en tan alto grado la lectura que la tendencia más habitual entre los críticos y estudiosos de María Zambrano ha sido recurrir a la paráfrasis" (Más allá de la filosofía. Sobre el pensamiento filosófico-místico de María Zambrano, 2000, Madrid, Siruela, pp. 427-428); concuerdo plenamente con la estudiosa danesa en que: "comprender un texto no consiste en parafrasearlo empáticamente" (ibid., 427). 
medida, a otros fenomenólogos - sobre los temas que vertebran el discurso de la andaluza, y sólo entonces indicar las afinidades, las apropiaciones y las modificaciones de los mismos por parte de Zambrano.

\section{La inmanencia psíquica}

En Los sueños y el tiempo Zambrano se afana una y otra vez en presentar a la conciencia en trance de constitución. Según este enfoque, el a priori del proceso de nacer es la psique: el fondo anímico de donde emerge el sujeto intelectual. Ahora bien, con todo y que la andaluza remite a su vez al alma a un sustrato orgánico último - el del cuerpo-, sería desafortunado interpretar esta doble implicación genética en los términos de un discurso fisicalista que pensara la instancia psíquica como producto de la interacción neuronal del cerebro humano. No hay que perder de vista que, por ecléctico que sea el léxico filosófico zambraniano, y por mucho que ella coquetee con el vitalismo y hasta con el biologismo, su pensamiento es de corte fenomenológico, y eso aquí significa que tanto el cuerpo como la psique de los que habla son instancias fenomenalizadas, es decir, tomadas en consideración desde la conciencia misma, como constructos intencionales. Dicho de otro modo, las instancias anímica y corpórea que facultan la constitución de la conciencia solo son descifrables en el discurso teórico de una conciencia ya constituida: "pues lo que inicialmente sorprendemos del sujeto humano es también fenómeno". ${ }^{15}$

En este tenor, la autora se refiere a la experiencia fenomenológica de lo psíquico como a una "enajenación inicial de alguien que busca identificarse", ${ }^{16}$ como a un "estado de inmanencia, que no parece ser propio de la vida humana" 17 y que no lo parece porque equivale a

una pre-vida donde [el sujeto] no se puede valer, donde la realidad no se le presenta, donde solo se siente a sí mismo, a su propia respiración,

${ }^{15}$ Los sueños y el tiempo, p. 19.

${ }^{16}$ Ibid., p. 16.

${ }^{17}$ Loc. cit. 
al latir de su corazón, al delicado esfuerzo de sus vísceras, donde sólo tiene el rumor inaudible de sus entrañas; la tensión que es consustancial a toda vida y ese apretarse sobre sí mismo en la unidad que es el ser humano, ese recogerse sobre sí y ese flotar en un océano sin contornos que no es la realidad sino la vida. ${ }^{18}$

Absorto en la psique, el sujeto (o su conato) experimenta una peculiar pasividad. Primeramente, hay que decir que se trata de una pasividad activa $\mathrm{o}$, en palabras menos contradictorias, de una pasividad manifiesta en forma de pura disponibilidad intencional. A decir de Zambrano,

la pasividad se le revela al hombre porque no está simplemente, porque no consiste en un yacer, en un inmutable estar ahí que se muestra y se hace presente [...] Porque tal pasividad se manifiesta, se hace presente porque se mueve. Es el sujeto quien la hace moverse. Es movida, su estado natural no es de reposo tampoco; por sí misma si no se mueve, se agita, está en tensión, en apetencia. La pasividad se da en la psique ante todo; allí yace el sujeto. ${ }^{19}$

Una segunda nota distingue a la pasividad psíquica: su experiencia plena no se da en la vigilia, sino en el dormir puro, sin sueños, lo cual lleva a la filósofa a concebir el estado del sujeto durmiente, esto es, su inmanencia anímica absoluta, como un análogo fenomenológico del punto de arranque del desarrollo de la conciencia. Esto es: cada vez que, al dormir, el yo suspende la actividad noética orientada hacia los objetos trascendentes del mundo, adopta esa configuración pasiva — vacía de contenidos vivenciales, aunque vigente como foco de irradiación intencional - que Zambrano concibe como la forma embrionaria del sujeto. Por ello conviene interpretar en términos antropológicos un aserto que parece trivial constatación empírica por parte de la andaluza: "el hombre duerme". ${ }^{20}$

En efecto, el hombre duerme y despierta, empírica, regular, circadianamente; pero además es una criatura cuyo domicilio ontológico

${ }^{18}$ Ibid., p. 66.

${ }^{19}$ Ibid., p. 25.

${ }^{20}$ Ibid., p. 43. 
originario es el sueño profundo y cuya conciencia se abre a la trascendencia del "mundo de la vida" desde el factum primordial de la pasividad activa, ese estado de latencia intencional: "Dormir es regresar. Volver a la situación prenatal, a estar inmerso dentro de algo inmenso, oscuro, invisible". ${ }^{21}$ Así las cosas, por el hecho fenomenológico constitutivo de que el hombre duerme, ocurre que en su dormir empírico "padece su propia ocultación, su inmanencia o estar, hasta hundirse en ella". ${ }^{22}$

En otros términos: la pasividad psíquica es el sustrato de la individuación. Según Zambrano, para el yo "dormir es una caída en una zona sobre la que emerge la vigilia. Es una pasividad que le retrotrae a la comunidad de los vivientes de la que se ha separado", ${ }^{23}$ a ese "océano sin contornos que no es la realidad sino la vida", ${ }^{24}$ en donde "acciones tan elementales, que de tan elementales son funciones, como respirar", ${ }^{25}$ se captan en una radicalidad vivencial que no es la de la apercepción del sujeto en vigilia, sino "algo más primario aún que ellas para el hombre: el sentir originario, cuyo diseño marcaría la estructura del vivir propiamente humano. El a priori de todo sentir, de todo sentimiento", ${ }^{26}$

Estamos aquí en el corazón del concepto zambraniano de pasividad. No se trata solamente de una experiencia que reduce al sujeto a ser mera tensión noética vacía, sino que lo disuelve en un plano de sensibilidad donde no existe, salvo quizá sólo como esbozo, la distancia fenomenológica que conforma la intencionalidad y faculta la conciencia. Dicho de manera más radical, en el plano de la inmanencia absoluta no hay siquiera conciencia potencial, sino pura apercepción sensible, por extravagante o impensable que a estas alturas del análisis semejante afirmación pueda parecer. Lo que puedo añadir por el momento es que la autora concibe esta dimensión última y radical de la pasividad como una experiencia inmediata de la carne, de

[1]o que la vida tiene de cuerpo, sustraído con frecuencia tanta a la consideración del pensamiento en su rigor, como olvidado también, ya que

${ }^{21}$ Ibid., p. 62.

${ }^{22}$ Ibid., p. 43.

${ }^{23}$ Loc. cit.

${ }^{24}$ Ibid., p. 66.

${ }^{25}$ Ibid., p. 55.

${ }^{26}$ Loc. cit. 
el haber un cuerpo permite el olvido de ello, cuando el sujeto asciende a su máxima actividad pensante, pues también aquí encontramos que la máxima actividad humana se ejerce a costa de la negación, del olvido. Y el cuerpo a solas, dejado, se despierta, llama soñando, se presenta en sueños: el animal, el simple viviente, y aun dentro del animal, el cuerpo material, el cuerpo hecho, integrado en lo que se llama "materia", integrado por organismos que obedecen y se ocultan en la unidad del organismo animal, del sujeto biológico. Y en ellos, la "materia" que de común con lo vivo tiene lo no vivo - lo no vivo ya o lo no vivo todavía - : la comunidad con lo que hay, con lo que la vida descubre y el tacto sugiere, con esa "materia" que se ofrece pasiva y extraña, distante, y que de algún modo el viviente arrastra, la materia sustraída a ese depósito, a esa remota arcilla, a esa inicial mezcla. El viviente arrastra esa mezcla y entre todos, el que vela, el hombre, sujeto activo sobre todos, impar, participa por ella, y no solo por el conocimiento, en todo el universo. Y viviendo a costa de ella también, la olvida, la olvida con solo estar vivo. Llevar hasta ella la autognosis, sería llegar a las puertas de la muerte. ${ }^{27}$

Importa retener de este pasaje que la noción de cuerpo, de materia pasiva, no es de naturaleza física sino fenomenológica: el cuerpo zambraniano es el ámbito de donación de veras mínima del sujeto, el de la experiencia aperceptiva básica, una experiencia dada en la antesala de la conciencia.

Valga ahora contrastar los asertos zambranianos sobre la pasividad con otras formas de pensamiento fenomenológico, en aras de despejar los remanentes de oscuridad que ha arrojado esta primera aproximación.

\section{El componente anímico de la inmanencia}

En el segundo libro de sus Ideas relativas a una fenomenología pura y una filosofía fenomenológica, Husserl estudia detalladamente no solo la constitución de la realidad trascendente como sistema de correlaciones intencionales en la conciencia, sino también (y esto es lo relevante para entender a Zambrano) la constitución de la conciencia misma. En

${ }^{27}$ Ibid., p. 35. 
este ámbito temático Husserl reconoce la existencia de una actividad del yo según la cual se ejecutan operaciones preconscientes que no alcanzan a cumplir el estándar de la intencionalidad plena:

En la esencia de la conciencia no radica, empero, que en ella tenga que ser necesariamente ejecutado un cogito actual. Nuestra "conciencia en vigilia" puede ser interrumpida a trechos por una conciencia durmiente, completamente sorda, en la cual no hay diferencia entre campo actual de la mirada y fondo oscuro. Todo es ahora fondo, todo es oscuridad. Al despertar del sueño sordo podemos llevar hacia atrás la mirada reflexiva, captar lo recién pasado en su ensordecimiento y abandono del yo: su abandono del yo activo, el que puede concebir, pensar, padecer-en-vigilia, etc. ${ }^{28}$

Nótese que Husserl no relaciona esta "conciencia sorda" con el estado al que llega el sujeto en el dormir empírico, sino que basta que cese el esfuerzo intencional de aprehensión plena que caracteriza a la atención vigilante para que ningún contenido vivencial se articule de manera activa, aun durante la vigilia; con todo, es claro que en el estado de indiferenciación aprehensiva que el autor describe hay un evidente isomorfismo con la idea zambraniana de que el sujeto en vela no es capaz de captar por completo "la masa de vivencias no elegidas para ser elevadas a sentires, percepciones y pensamientos", ${ }^{29}$ de manera que un buen número de ellas son asimiladas imperceptiblemente y se depositan en el fondo de la psique:

La persistencia de la atención logra continuidad y transparencia, convierte el fluir de la vida en un cierto modo del ser, anuncia ya el ser. Y esto lleva tiempo, consume tiempo. El que se toma el sujeto para sí y que regala a las vivencias privilegiadas, elegidas por su atención. Y mientras las demás se desvanecen o quedan rondando ávidamente alrededor del

${ }^{28}$ Edmund Husserl, Ideas relativas a una fenomenología pura y una filosofía fenomenológica. Libro segundo: Investigaciones fenomenológicas sobre la constitución, 2005, México, Universidad Nacional Autónoma de México/FCE, p. 144. En adelante, cito esta obra como Ideas II.

${ }^{29}$ Los sueños y el tiempo, p. 81. 
círculo de claridad central [...] lo que les sucede a estos sentires y pensamientos larvarios es que se pierden, que se desprenden y precipitan en una especie de remolino [...] en los infiernos de la temporalidad. ${ }^{30}$

También es preciso percibir que el mecanismo de sedimentación inconsciente del modelo teórico de la andaluza es compatible con la estructura estándar de la conciencia husserliana - la que distingue un foco claro y destacado, de un horizonte desatendido de datos intencionales - aunque aquí se deja ver una diferencia: la "conciencia sorda" de Husserl no es absorción inconsciente exclusiva de los correlatos intencionales residuales del segundo plano del campo perceptivo - como en Zambrano- , sino más bien captación inconsciente de un tramo entero de contenidos vivenciales. Así las cosas, la idea zambraniana más conforme al concepto de "conciencia sorda" es la de cierta modalidad noética a la que en Los sueños y el tiempo se le dedica un mínimo pasaje: el "ensoñar", una forma de actuar del sujeto según la cual "el contenido de la conciencia que no ha cesado es indiscernible, por no ser representativo. Es meramente sensible, huidizo y semitransparente, pues que no se trata de visión alguna, de modo alguno de ver, sea intuición de realidad presente, sea representación formada por recuerdo o intención". ${ }^{31}$ Ahora bien, si buscamos el fundamento o la condición de posibilidad de la conciencia pasiva husserliana llegamos a un a priori, el de la sensibilidad anímica, el "SUBSUELO OSCURO [...] de disposiciones primigenias y latentes, y [...] dependiente de la naturaleza", ${ }^{32}$ sobre el cual, el autor apunta:

El haz de vivencias perteneciente al hombre no es meramente un haz de vivencias, o una mera "corriente" de conciencia en la cual nadan las vivencias; más bien todo vivenciar es vivenciar de un yo, que no corre él mismo como sus vivencias. Y ahí está constantemente un subsuelo que el yo tiene predado, un múltiple estar-referido a ello o ser impulsado; un ejecutar de actos específicos y a una con ello un constante enri-

${ }^{30}$ Loc. cit.

${ }^{31}$ Ibid., p. 93.

${ }^{32}$ Ideas II, p. 324. Las versalitas siempre son de Husserl. 
quecimiento de la corriente de vivencias que se logra desde el yo mismo: su imperar yoico se vuelve eo ipso vivenciar. ${ }^{33}$

Este sustrato soporta la estructura de la Zeitbewusstsein, ${ }^{34}$ de la conciencia constituyente del tiempo sucesivo de la vigilia, y a la vez opera como depósito de los remanentes periféricos de los actos intencionales cabalmente cumplidos, de manera que ahí, en el oscuro fondo del alma se alojan:

vivencias de cualesquiera especies, y justo o bien de aquellas que son "sedimentos" de actos de razón u obras de razón anteriores, o que, por "analogía" con aquellas, se presentan como unidades aperceptivas sin estar realmente formadas por la acción racional [...] Ahí lo singular está motivado en el subsuelo obscuro, tiene sus "FUNDAMENTOS anímicos" POR LOS CUALES PUEDE PREGUNTARSE: ¿CÓMO LLEGÓ AHÍ?, ¿qué me ha llevado a eso? ${ }^{35}$

Con lo dicho hasta aquí es posible hacerse una idea más clara de la adscripción del pensamiento de la andaluza en este orden de cosas a la fenomenología canónica; se puede ver que la condición de la psique

${ }^{33}$ Ibid., p. 325.

${ }^{34}$ Husserl concibe la conciencia del tiempo como una estructura distendida que faculta la captación de las vivencias intencionales desde un foco de atención presente que se prolonga sin solución de continuidad hacia el pasado psíquico en la forma de una retención de lo ahora captado, captación que se complica por la añadidura constante de nuevas vivencias que modifican el escorzo retencional de las previas, al que se incorporan generando una retención de retenciones, o modificación de modificaciones: "El continuo constituyente de tiempo es un flujo de constante producción de modificación de modificaciones. A partir del ahora actual, a partir de la correspondiente impresión originaria $i$, las modificaciones discurren en el sentido de iteraciones pero en constante avance; no solo son modificaciones en relación con $i$, sino también, según la serie, modificaciones unas de otras en la sucesión seriada en que discurren" (Edmund Husserl, Lecciones de fenomenología de la conciencia interna del tiempo, 2002, Madrid, Trotta, p. 120. En adelante, cito esta obra como Lecciones). En otras palabras: "en el flujo de conciencia uno, único, se entrelazan dos intencionalidades inseparablemente unitarias, que se requieren la una a la otra como dos caras de una y la misma cosa. Por la primera de ellas se constituye el tiempo inmanente, un tiempo objetivo, auténtico tiempo, en el cual hay duración y hay cambio de lo que dura. En la otra intencionalidad se constituye la ordenación quasi-temporal de las fases del flujo, que tiene necesariamente un punto-'ahora' fluyente, las fases de actualidad y las series de fases preactuales y postactuales — las que todavía no son actuales_- (Ibid., p. 102. Las cursivas son de Husserl.)

${ }^{35}$ Ideas II, p. 269. 
zambraniana se corresponde con la esfera de lo anímico "predado", en la que Husserl fundamenta la actividad del sujeto constituido como cogito. Recapitulando: en ambos casos se piensa que el funcionamiento intencional del yo en vigilia atenta presupone un ámbito de pasividad activa que opera, cuando menos, de tres maneras: a) como plano de aprehensión secundario de las vivencias inactuales que entran al campo perceptivo por la periferia del foco de atención; $b$ ) como sede de los actos de captación intencional "sorda" — el caso del "ensueño" zambraniano- - y c) como sustrato último de sedimentación de los contenidos noemáticos inactuales percibidos, ya por la conciencia convencional, ya por la conciencia "durmiente". Empero, la correspondencia entre los dos modelos de inmanencia psíquica alcanza su mayor grado de visibilidad si se añade al análisis el del fenómeno del tiempo.

Resulta coherente concebir la forma básica del tiempo psíquico zambraniano, la duración, ese "tiempo vacante, extensión temporal sin movimiento que la ocupe", ${ }^{36}$ como análoga a la corriente temporal inmanente absoluta a la que Husserl llama Zeitbewusstsein. En sus Lecciones de fenomenología de la conciencia interna del tiempo, el filósofo lleva el estudio de la nootemporalidad ${ }^{37}$ a sus límites expositivos cuando afirma que no tiene más recursos para describir la naturaleza última de la Zeitbewusstsein que los que le ofrecen los objetos temporales ya formados en el interior del decurso de la conciencia impresional-retencional, puesto que, en puridad, el "continuo constituyente de tiempo", el "flujo de constante producción de modificaciones de modificaciones", 38 "es algo que denominamos así según lo constituido, pero que no es nada objetivo en el tiempo. Es la subjetividad absoluta y tiene las propiedades de lo que en imagen designamos como 'flujo', 'río' [...] Para todo esto nos faltan los nombres". 39

${ }^{36}$ Los sueños y el tiempo, p. 73.

${ }^{37}$ Tomo en préstamo este neologismo de Giacomo Marramao: "Nootemporalidad o tiempo noético: representada por una flecha bien definida, con punta, asta y cola (una flecha, pues, direccionada). Es la imagen del tiempo que pertenece exclusivamente a la mente humana madura, a la conciencia. Un tiempo caracterizado por una clara distinción entre pasado y futuro, unos ilimitados horizontes de memoria y expectativa, un presente mental con fronteras temporales variables en función de la atención" (Kairós. Apología del tiempo oportuno, 2008, Barcelona, Gedisa, pp. 73-74).

${ }^{38}$ Lecciones, p. 120.

${ }^{39}$ Ibid., p. 95. 
Ahora bien, en los análisis de Ideas II Husserl tiene que lidiar con la misma penuria conceptual y lingüística, y ya no sólo por las dificultades descriptivas que ofrece el fenómeno del nootiempo, sino porque al estudiar el sustrato anímico de la conciencia "es difícil enviar miradas reflexivas al reino de las oscuridades y llegar a estar seguro de lo que en esa esfera se da" ${ }^{40}$ Con todo, en este otro libro sobre la constitución de la subjetividad, el autor se esfuerza por articular de manera congruente el carácter temporal de la conciencia con el hecho de su fundamentación en lo anímico. Así, en un pasaje que cité arriba, Husserl afirma que "todo vivenciar es vivenciar de un yo, que no corre él mismo como sus vivencias" y que "ahí está constantemente un subsuelo que el yo tiene predado [...] y a una con ello un constante enriquecimiento de la corriente de vivencias que se logra desde el yo mismo". ¿Cómo conciliar estas proposiciones con aquella que identifica al continuo constituyente de tiempo con la subjetividad absoluta? Por principio de cuentas, notando que, al escribir que "el yo no corre como sus vivencias", el autor no está pensando en el sujeto en los términos del cogito cartesiano, esto es, como ajeno a la temporalidad, sino más bien en uno cuya temporalidad inmanente no tiene la contextura objetiva de las vivencias, justo porque él mismo es el acto de producir el nootiempo, de articular de manera impresional-retencional cualquier vivencia; con lo cual no se dice que el yo último no fluya, sino solamente que no fluye como uno de sus contenidos. ¿Cómo, entonces? Husserl explica:

Yo soy siempre el mismo, pero en la corriente cambiante de las vivencias, en las cuales muy frecuentemente se constituyen motivos nuevos. Veo aquí por tanto una legalidad esencial del yo puro. Pertenece, en cuanto este yo idéntico, numéricamente uno, a "su" corriente de vivencias, que está constituida como una unidad del tiempo inmanente infinito. El yo puro uno está constituido como unidad con referencia a esta unidad de la corriente, esto es, puede hallarse como idéntico en su curso. Puede por tanto mirar atrás, en recuerdos, las cogitaciones anteriores y hacerse consciente de sí

${ }^{40}$ Ideas II, p. 144. 
como el sujeto de estas cogitaciones recordadas. Ya en ello hay una especie de consecuencia del yo. Pues un yo "estable y permanente" no podría constituirse si no se constituyera una corriente de vivencias estable y permanente, o sea, si las unidades de vivencias originariamente constituidas no fueran acogibles de nuevo, si no fueran capaces de presentarse de nuevo en recuerdos, y presentarse con la asunción de su cualidad de ser (como existentes en el tiempo inmanente). ${ }^{41}$

Según esto, el yo es idéntico a sí mismo, pero no por invariancia de sus contenidos vivenciales, ni porque sea inmune a las modificaciones operadas en él por la experiencia del vivenciar, sino más bien porque se puede reconocer como el mismo (identidad-idem, diría Ricoeur), a pesar de las modificaciones ejercidas en él por la diversidad de lo vivenciado; mejor aún, se puede reconocer como el mismo yo gracias a su invariancia como foco noético en cada "inmersión" en su propio decurso temporal, o bien, como dice Husserl, porque "pertenece, en cuanto este yo idéntico, numéricamente uno, a 'su' corriente de vivencias".

Lo decisivo, empero, está por llegar. De momento es un hecho que

[ $\mathrm{t}$ ]odas las unidades de duración que se edifican en el flujo continuo del tiempo inmanente, se encadenan en la unidad de la corriente de conciencia monádica en constante devenir y crecer, con el yo puro inherente a ella. Aquí, este yo puro se fija mediante un cogito determinado cualquiera; se prolonga hacia la esfera total de lo que, en el sentido de la posibilidad ideal, es por él absoluta e inmanentemente perceptible, recordable, esperable, incluso fantaseable, según todos los modos temporales. ${ }^{42}$

Ahora bien, también es un hecho que la "prolongación" de la conciencia impresional-retencional hacia los horizontes del pasado y del futuro solo es ilimitada como mera posibilidad. Una Zetibewusstsein ya no posible sino fáctica es incapaz de sostener los actos retencionales y protencionales en una continuidad sin fin; el "campo del tiempo" de la conciencia humana tiene un capacidad de retención y protención

${ }^{41}$ Ibid., p. 150.

${ }^{42}$ Ibid., p. 157. 
limitadas; es justo eso lo que faculta la constitución del recuerdo secundario - la rememoración - y de la expectativa teleológicamente orientada. Como dice Hans Blumenberg: "Esencialmente necesarias a una conciencia, para que sea capaz de objetos, son solo la retención y la protención, es decir, el presente modificado o ampliado, no el pasado o el futuro. En cambio, todo pasado, si es que aparece en una conciencia, está en el continuum latente de la retención; todo futuro, que solo aparece si aparece el pasado, en el continuum latente de la protención". ${ }^{43}$ A lo que añade:

Por esencia, la retención y la protención son infinitas. En tanto son necesarias para una conciencia en general, esta es infinita en sus dos direcciones, o en todo caso solo está limitada fácticamente según la analogía del horizonte, que también siempre solo es relativo a un determinado punto de vista, pero del que nadie supone que allí se llegaría a un límite real. En la conciencia de un ser mundano (es decir, de lo que Heidegger llama estar-en-el-mundo), eso se nota en que directamente es imposible experimentar, recordar o esperar el inicio o el fin de la corriente de conciencia, ni siquiera es posible pensarlos. Del nacimiento y la muerte, el sujeto se entera indirectamente, por otros y de otros. ${ }^{44}$

En vista de todo esto cabe preguntarse una vez más cómo es posible la identidad husserliana, esto es, el reconocimiento del yo en la corriente de vivencias a la que es inherente, si mediante la conciencia no se puede abarcar en un solo acto retencional-protencional la totalidad de la corriente, sino solamente tramos suyos o recortes operados en ella, y eso solo en virtud de actos discretos de intencionalidad secundaria, como lo son el recuerdo reproductivo y la expectativa planeada. Dicho de otro modo, si "el recuerdo es siempre una falta de autenticidad de la conciencia, su debilidad para ser completamente ella misma", ${ }^{45}$ si la conciencia limitada y separadora del sujeto no puede garantizar la unidad de la corriente vivencial en la que se funda en último análisis la iden-

${ }^{43}$ Hans Blumenberg, Descripción del ser humano, 2011, Buenos Aires, FCE, p. 134.

${ }^{44}$ Loc. cit.

${ }^{45}$ Ibid., p. 139. 
tidad, ¿dónde es pese a ello dable a ese yo la experiencia del reconocimiento en la unidad de la corriente? Husserl responde: en el subsuelo anímico, en la esfera de lo predado, ahí donde la temporalidad inmanente fluye sin interrupción, en una continuidad automática operada por las síntesis pasivas que el sujeto ejecuta en la protoforma de la actividad consciente. En sus palabras:

Por necesidad esencial, la vida del alma es un flujo; obviamente le falta, por ende, algo análogo a una forma espacial en cuanto forma de realidades existentes posiblemente inalteradas. Ahora bien, con la necesidad de la alteración de los estados está dada en el alma la NECESIDAD DE LA MENCIONADA ALTERACIÓN DE LAS PROPIEDADES ANÍMICAS mediante innovación de disposiciones: toda vivencia lega disposiciones y crea algo nuevo con respecto a la realidad anímica. Esta misma es, por ende, una realidad que constantemente se altera. ${ }^{46}$

A lo que vale la pena añadir esto otro:

A la esencia de la REALIDAD ANÍMICA pertenece el NO poder retornar por principio al mismo estado total: las realidades anímicas tienen precisamente una HISTORIA. Dos ciclos de circunstancias externas contiguos uno del otro afectarían de igual manera la misma alma, pero en el alma misma los cursos anímicos de los estados no podrían ser los mismos, porque el estado anterior determina funcionalmente al posterior. ${ }^{47}$

Así, la constitución pasiva del subsuelo anímico también como un flujo - y como uno en el que por esencia no hay dos contenidos vivenciales idénticos - no solo faculta la aptitud de la conciencia de acudir mediante actos separados a segmentos de su corriente vivencial, sino que, a fin de cuentas, soporta el edificio completo de la identidad.

Este recorrido por los caminos de Husserl permite entender de manera más precisa la realidad temporal de la inmanencia psíquica zambraniana, sobre todo en lo tocante a sus dos notas características: a) la continuidad $\sin$ fisuras de la duración, esa forma del nootiempo que "no

${ }^{46}$ Ideas II, p. 172.

${ }^{47}$ Ibid., p. 176. 
es un transcurrir sino un seguir, una dilatación que no detiene la marcha del tiempo para quien a él está apegado"; 48 b) el hecho de que funcione como lecho de las vivencias desatendidas y, en suma, de todo el sedimento experiencial que forma el pasado del sujeto, pues la duración es un depósito dinámico en el que "queda lo no elegido por la claridad de la conciencia". ${ }^{49}$

Señalé un poco más arriba que la limitación retencional-protencional de la conciencia se debe a la facticidad de la vida humana, y que los actos discretos de la memoria y la expectación son el remedio a esa condición. Como dice Blumenberg: "el recuerdo y la expectativa serían directamente funciones sustitutas del hecho de que no se puede mantener el continuum creado por la retención y la protención en torno al presente como impresión originaria". ${ }^{50}$ Lo que ahora me interesa destacar es el vínculo que hay entre la imposibilidad de una conciencia continua absoluta y la estructura de la distancia intencional; es decir, el hecho de que una conciencia que no tuviera necesidad de constituir sus recuerdos como entidades de segundo grado, como reproducciones discretas de tramos del flujo vivencial primario, tampoco sería susceptible de disociarse cabalmente en un polo noético y otro noemático y permanecería inmersa en la esfera anímica de lo que Husserl llama "predado", pues no tendría necesidad de ninguna donación intencional. En palabras de Blumenberg:

Esto no es más que la descripción circunstanciada del hecho de que la reflexión forma parte del recuerdo [...] porque en la reflexión la conciencia tiene que alejarse de sí para poder volver sobre sí misma, porque siempre vuelve sobre sí misma en la unión de cogito y cogitatum. Solo una conciencia que también pudiera realizar la retención ilimitada de por sí no necesitaría o ni siquiera podría alejarse de sí ni volver sobre sí. ${ }^{51}$

Esto es relevante en el contexto de la filosofía de la forma-sueño, porque deja entender la tesis zambraniana de que el yo no puede permanecer en la inmanencia psíquica si quiere ser sujeto pleno, despierto

${ }^{48}$ Los sueños y el tiempo, p. 72.

${ }^{49}$ Ibid., p. 81.

${ }^{50}$ Descripción del ser humano, p. 135.

${ }^{51}$ Ibid., p. 133. 
y consciente. En la medida en que la psique es la recolección continua de todo el nootiempo de un individuo, cuando el yo duerme logra de alguna manera — así sea opaca o "sorda", como dice Husserl— esa "retención ilimitada" que le impide alejarse de sí mismo, es decir, constituir la estructura cogitativa dual de la intencionalidad.

\section{El componente corpóreo de la inmanencia}

Atendamos ahora lo segundo que quedó pendiente: la dimensión corporal de la pasividad zambraniana. Es este el ámbito más radical de la experiencia de sí mismo; una región a la que el sujeto accede obliterando su conciencia trascendente y fusionándose consigo mismo en la inmersión psíquica del dormir profundo, sin actividad onírica. Una vez ahí, el yo casi cesa de ser yo, es un mero conato; o, mejor aún, es la posibilidad de su propio conato, pues ni siquiera experimenta la apetencia de salir de sí, esa labilidad que lo dispone, dormido pero soñando, a despertar a la conciencia plena. La máxima cercanía del sujeto a su cuerpo se refleja sobre todo en la esfera de lo temporal. De acuerdo con Zambrano, la experiencia de la duración durmiente parece anularse como temporalidad psíquica en el sueño profundo y fusionarse por su límite inferior con el biotiempo, ${ }^{52}$ el correspondiente al organismo, que ya no es siquiera un seguimiento anodino, vacío de contenidos intencionales, sino un mero ritmo metabólico:

Está sumido [el durmiente] en la vida, sin tiempo propio, en el tiempo de la vida misma si en ella lo hay. Más si lo hay él no lo puede medir ni contar. Solo puede contarse a sí mismo como mecanismo viviente, a los latidos de su corazón, a su tiempo visceral que no es un tiempo disponible. El tiempo visceral es el latir mismo de la vida, o a lo menos con

${ }^{52}$ De nuevo un préstamo de Marramao: "Biotemporalidad o tiempo biológico: representada por una flecha con punta y cola poco definidas, aunque aún pueden distinguirse. Es la realidad temporal de todos los seres vivos (incluido el hombre, si bien limitado a sus funciones biológicas). Aquí también se da una distinción entre los tres tiempos, aunque en distinto grado según las especies, y el presente consciencial del nivel nootemporal se sustituye por el presente orgánico del proceso vital" (Kairós. Apología del tiempo oportuno, p. 74. Las cursivas son del autor). 
él se confunde; es su manifestación. Y el hombre que se dispone a dormir funde todos sus tiempos en el tiempo de la vida. Su latir se torna manifestación del latir elemental de la vida, se reúne en el concierto de todo lo viviente..$^{53}$

La autora entiende este biotiempo o "tiempo visceral" como el sustrato último de la constitución del sujeto, como el plano originario que faculta su emergencia, en la medida en que la visceralidad rítmica es manifestación del cuerpo al que la psique está ligada, y también en virtud de que el subsuelo corpóreo tiene cierto grado de alteridad anónima: el cuerpo zambraniano es el reino de la preindividuación; esto quiere decir que la "carne" es materia disponible para originar la subjetividad, mas no aún materia dispuesta (en el sentido activo del participio) pues solamente la psique es la sede del conato intencional, de la propensión a la conciencia. En consonancia con todo esto, Zambrano dice que "no se hunde el hombre en el sueño, sino que queda alojado en él, abrigado, recogido. Desnudo y envuelto. Envuelto en la última envoltura que es el tiempo físico que lo recoge sin devorarlo". ${ }^{54}$

Es preciso insistir en que este lenguaje fisicalista no deja de ser un recurso retórico, y en que se debe entender la experiencia del sujeto fundido al cuerpo como fenomenalizada, por contradictorio que sea concebir stricto sensu un hecho fenomenológico, ya no solamente digamos anclado en un polo noético suturado a su correlato fenomenal (como ocurre en la estructura de la psique), sino que ni siquiera en potencia distingue tal polaridad, por tratarse, en el caso de la carne, de la inmediatez inmanente absoluta. Como dice Paul Ricoeur:

Que la carne es lo más originariamente mío y la más próxima de todas las cosas; que su aptitud para sentir se manifiesta por privilegio en el tacto [...] estos rasgos primordiales hacen posible que la carne sea el órgano del querer, el soporte del libre movimiento; pero no puede decirse que son el objeto de una elección, de un querer. Yo, en cuanto este hombre: esta es la alteridad primera de la carne respecto a cualquier

${ }^{53}$ Los sueños y el tiempo, p. 68.

${ }^{54}$ Ibid., p. 70. 
iniciativa. Alteridad significa aquí primordialidad respecto a cualquier intención. A partir de esta alteridad yo puedo reinar sobre. Pero la primordialidad no es reino. La carne precede a cualquier distinción entre lo voluntario y lo involuntario. Es cierto que podemos caracterizarla por el "puedo"; pero precisamente "puedo" no deriva de "quiero", sino que le da raíz. La carne es el lugar de todas las síntesis pasivas sobre las que se edifican las síntesis activas, las únicas que pueden llamarse obras (Leistungen): ella es la materia (hyle) en cualquier objeto percibido, aprehendido. En una palabra, ella es el origen de toda "alteración de lo propio". De estas resulta que la ipseidad implica una alteridad "propia", si se puede hablar así, cuyo soporte es la carne. ${ }^{55}$

Si la carne es primordial, es "territorio" mas no reino; solo se puede "reinar sobre" cuando está constituida la distancia fenomenológica; por ello, paradójicamente, el cuerpo es lo más “mío", pero es tan mío que no acaba de tener dueño; es la pasividad completa, y, sin embargo, Ricoeur asigna a la carne, como lugar de las síntesis pasivas, el mismo estatuto preconsciente que Husserl al oscuro sustrato anímico y la filósofa andaluza a la psique como tal. Es decir, Ricoeur habla del cuerpo como "la más próxima de todas las cosas", y lo más próximo indica todavía distancia, aun cuando esa distancia se piense en los términos de la conciencia "sorda" husserliana, o en los de la inmanencia psíquica de nuestra autora; sigue por lo tanto pendiente esclarecer por completo la índole de la carne zambraniana. Las perplejidades se acumulan, al grado de lo aporético; sobre todo esta: ¿cómo conciliar el hecho primigenio del cuerpo con su facultad de abrir la estructura dual de la conciencia si la carne parece refractaria a la partición?

Según las contribuciones fenomenológicas de Michel Henry al tema de la constitución de la conciencia, el "cuerpo subjetivo" o "cuerpo originario" es la instancia fundacional última. Este cuerpo no es más que la apercepción inmediata absoluta; está "predado" en una radicalidad inconsciente total. Henry se refiere a él como a "algo anterior que es perfectamente autosuficiente y que en modo alguno exige la intervención de un juicio que lo exprese para alcanzar su plenitud, que

${ }^{55}$ Sí mismo como otro, p. 360. 
es, pues, lo absolutamente concreto, es la 'intuición inmediata' o 'apercepción interna', es decir, la experiencia interna trascendental", ${ }^{66}$ $\mathrm{y}$ al respecto propone

que el cuerpo se nos da en una experiencia interna trascendental, que el conocimiento que tenemos de él es verdaderamente un conocimiento originario y, por consiguiente, que el ser del cuerpo pertenece a la región ontológica donde son posibles y acontecen tales experiencias internas trascendentales, es decir, a la esfera de la subjetividad. El ser fenomenológico (es decir, originario, real y absoluto) del cuerpo es, pues, un ser subjetivo. Con ello se afirma asimismo la inmanencia absoluta del cuerpo, afirmación que implica el rechazo de todos los análisis presididos por la presuposición de que el cuerpo sea en su ser originario algo trascendente, la cual casi siempre viene implícita, pues, entre las muchas afirmaciones que se dan por sentadas, ocupa sin duda un lugar de honor aquella de que el cuerpo es una cosa, una realidad constituida y una parte del mundo. ${ }^{57}$

Henry otorga al concepto de cuerpo en tanto que trascendental —en el sentido kantiano de condición de posibilidad del sujeto — una doble valencia: por una parte, es la apercepción inmediata; pero también ocurre que esa certeza de sí originaria está espontáneamente abierta a la trascendencia:

Al mismo tiempo que una experiencia interna trascendental, nuestro cuerpo es una experiencia trascendente. Precisamente porque el saber de sí del cuerpo originario no es un saber temático, porque el "sí mismo" y la ipseidad del cuerpo no son la conclusión sino la condición de tal saber, este saber no está cerrado sobre sí, no es el saber de sí mismo, sino el saber del ser trascendente en general. Encontramos aquí de nuevo el ser de la subjetividad absoluta en su raíz y en su estructura más profunda. Puesto que tal ser no está constituido, es un poder de constitución; puesto que se da a sí mismo, sin que en ese acto de darse a sí mismo

${ }^{56}$ Michel Henry, Filosofia y fenomenología del cuerpo. Ensayo sobre la ontología de Maine de Biran, 2007, Salamanca, Sígueme, p. 47.

${ }^{57}$ Ibid., pp. 94-95. 
aparezca en ningún momento en el elemento del ser trascendente, tal región del ser trascendente queda libre ante él y algo puede serle dado en ella. ${ }^{58}$

Según esto, la indiscernibilidad del yo respecto a sí mismo en la experiencia del cuerpo subjetivo es la condición de posibilidad de la distancia fenomenológica, y ello porque, al no ser la apercepción inmanente un hecho temático (es decir, objetivado como correlato intencional), puede fungir como fundamento de todos los hechos temáticos. En otras palabras: la conciencia de objeto no está fundada en una autoconciencia o conciencia refleja previa, con la que compartiría la estructura de la distensión intencional (en el primer caso orientada "hacia fuera"; en el segundo, revertida "hacia adentro"), pues entonces la conciencia de objeto no sería más que una variante de la conciencia refleja, y en esta otra hallaríamos establecida ya desde el principio la forma de la intencionalidad, en cuyo caso no se daría ni la inmanencia radical (ya que la apercepción no sería inmediata) ni la trascendencia plena (pues toda orientación hacia el mundo sería subsidiaria de una orientación de la conciencia hacia sí misma, y entonces el "saber temático" estaría "cerrado sobre sí"). Por el contrario, en el pensamiento de Henry es indispensable para que haya conciencia que antes haya cuerpo, y que el cuerpo no sea consciente de sí en absoluto; solo en virtud de la autodonación inconsciente del cuerpo puede este mismo manifestarse como conciencia intencional:

Los poderes de mi cuerpo solo me entregan, pues, el ser del mundo a condición de pertenecer a la esfera de la inmanencia absoluta, a condición de ser conocidos dentro de un conocimiento donde no interviene el concepto de mundo. Ahora bien, el conocimiento del mundo por el cuerpo y el conocimiento originario del cuerpo por sí mismo no son dos conocimientos diferentes, dado que el segundo es la sustancia misma del primero. La experiencia trascendente es, en sí misma, una experiencia interna trascendental: la experiencia originaria es una experiencia en la que nos son presentes el ser del mundo y el ser del cuerpo, aunque el modo en que se efectúa esta presencia sea radicalmente diferente en cada

${ }^{58}$ Ibid., p. 139. 
caso: el cuerpo, en la inmanencia absoluta de la subjetividad; el mundo, en el elemento del ser trascendente. ${ }^{59}$

En su radicalidad, la experiencia subjetiva es la del cuerpo (inmanente) y, en la del cuerpo, la del mundo (trascendente). Para describir este fenómeno con más precisión, Henry desdobla el concepto de cuerpo en un cuerpo originario (del que he venido hablando) y un cuerpo orgánico, que no es otra cosa que la hipóstasis del momento o aspecto trascendente del primer cuerpo. ${ }^{60}$ De hecho, sólo hay un cuerpo, el originario, dado en sus dos aspectos de una misma vez; con todo y que dichos aspectos son inseparables, en el plano del análisis se puede distinguir el momento aperceptivo del momento intencional, para con ello mostrar que el segundo es una prolongación de los poderes del primero. Así, el llamado cuerpo orgánico es

una zona de intercambio entre la subjetividad y el ser [...] Tal zona de intercambio, a la que hemos dado el nombre de distancia fenomenológica, efectivamente existe, pero sabemos que requiere un fundamento y que ese fundamento reside justamente en la esencia de la verdad originaria de la subjetividad. La subjetividad no es, pues, un término que en sí mismo fuese abstracto, sino que, lejos de que encuentre su realidad y culminación en el ser trascendente del cuerpo orgánico al que está inmediatamente unida conforme a una relación trascendental, resulta ser en cambio el fundamento de tal ser que, en cuanto término hacia el que se trasciende, se nos presenta como su límite, si bien un límite que aún le pertenece. ${ }^{61}$

Queda sólo un elemento por integrar a este modelo teórico: la temporalidad. Henry distingue el biotiempo del cuerpo originario del nootiempo del cuerpo orgánico; esta distinción implica una jerarquía: el

${ }^{59}$ Ibid., p. 140.

${ }^{60}$ De hecho, la teoría de Henry distingue tres cuerpos: el originario, el orgánico (que expondré enseguida) y el objetivo - del que no me ocupo en este texto-: "que es objeto de una percepción exterior y que puede ser tema de estudio científico, es el único que reconoce la tradición filosófica, y precisamente esta concepción objetiva exclusiva es la que ha dado lugar a multitud de falsos problemas - en especial al célebre problema de la unión del alma y el cuerpo- así como a muchas otras teorías que se esfuerzan, sin demasiado éxito, en resolverlos" (Ibid., p. 189).

${ }^{61}$ Ibid., p. 183. 
segundo modo temporal está constituido por el primero, lo cual significa que la Zeitbewusstsein está fundada en un sustrato que ya no puede concebirse como flujo, ni siquiera como el del subsuelo anímico husserliano, sino tan solo como un brotar el tiempo directamente de la apercepción inmanente:

Esta unidad de mi ser a lo largo del tiempo constituida por la memoria requiere un fundamento. Tal fundamento es el hábito, o si lo preferimos, el ser mismo de mi cuerpo que precisamente hace posible el acto de memoración y que no es sino el ser del conocimiento ontológico entendido como el ser real de la pura posibilidad. Explicar la unidad del ego o del cuerpo a partir de la memoria es cometer un paralogismo, es explicar la unidad originaria por una facultad que, justo al contrario, se funda sobre tal unidad. Dicho en otras palabras, la unidad de nuestro ser no está constituida, no está arrancada al tiempo gracias al poder de nuestras protenciones y retenciones, sino que es inmanente al ser de nuestro conocimiento ontológico, se confunde con él, es precisamente aquello que hace de este ser el ser de un conocimiento ontológico. ${ }^{62}$

En su forma originaria, entonces, la experiencia del tiempo no es la de una conciencia del fluir impresional-retencional, sino la de un sentimiento del mero estar el cuerpo dado a sí mismo, es “el borboteo interior del saber en cuanto tal saber es una vida". ${ }^{63}$

Si volvemos ahora de la mano del pensamiento de Henry al tema de la psique zambraniana encontramos que, así como el cuerpo originario es al mismo tiempo concentración absoluta del yo en sí mismo y apertura intencional como cuerpo orgánico, el alma, para la andaluza, presenta una dualidad aspectual parecida: por una parte, está ligada a la vida como a su último sustrato, encapsulada en ella, o, mejor, fusionada con ella; la apercepción del sujeto zambraniano toca aquí su límite inferior; sabemos que la experiencia de este límite se da en un estado de inconciencia total, como un mero sentir originario del yo previo a cualquier tensión intencional; estamos también al tanto de que el medio

${ }^{62}$ Ibid., p. 148.

${ }^{63}$ Ibid., p. 232. 
temporal en que ocurre esta experiencia no puede llamarse propiamente fenomenológico: es el tiempo de las vísceras, que tan solo se anuncia al sujeto o en el sujeto como un pulso, sin articularse aún como flujo ininterrumpido, esto es, como duración. Pero la psique tiene también un segundo aspecto, según el cual ya está conformada como instancia fenomenal, pues se siente a sí misma correr en el río de la duración; este sentir secundario puede interpretarse como análogo al cuerpo orgánico de Henry, en la medida en que la vivencia de sí mismo como un fluir por el tiempo presupone ya, aun cuando en forma embrionaria, la distancia fenomenológica: no se olvide que en el dormir durativo el sujeto percibe su propio "pasar" o "ir monótonamente [por un] tiempo vacante, extensión temporal sin movimiento que la ocupe", ${ }^{64}$ es decir, por un tiempo sin contenidos vivenciales en el que, sin embargo, un polo noético está abierto a los correlatos noemáticos aunque ellos no se den; alcanza aquí la psique su límite superior, su apertura a la conciencia plena; en contacto con este segundo límite, el sujeto se sitúa en el umbral que separa a la duración de la sucesión, es decir, a la temporalidad vacía constituida por síntesis pasivas —el flujo anímico husserliano — de la temporalidad de las síntesis activas operadas conscientemente.

\section{La trascendencia de la conciencia}

En el estado de vigilia el yo comparece consciente ante a la realidad gracias a que ha constituido la distancia fenomenológica que lo posiciona frente a y lo dirige hacia los objetos trascendentes que el mundo le ofrece y que él fenomenaliza en forma de vivencias ordenadas según el flujo de la nootemporalidad. Este fluir no resulta de una sola captación continua retencionalmente ilimitada, sino que es más bien una serie de actos impresionales-retencionales eslabonados. En la sucesión, el sujeto "vive estando presente, en un presente que es estar presentándose, sosteniéndose en ese presente que se reitera en actos ininterrumpidos: se sucede a sí mismo" ${ }^{65}$ En la vigilia consciente, dice la autora,

${ }^{64}$ Los sueños y el tiempo, p. 72.

${ }^{65}$ Ibid., p. 37. 
el sujeto "comparece", es decir, emerge de la psique a la trascendencia del mundo, y ejecuta esa comparecencia sostenidamente, mediante el ejercicio reiterado de la intencionalidad; de ahí esa "tensión para mantenerse en estado coherente, en una unidad que reúne y alza, que hace emerger su presencia como salida de un fondo donde naturalmente tendiese a volver". ${ }^{66} \mathrm{Y}$, en efecto, periódicamente vuelve el yo a ese fondo, cada vez que duerme; empero, mientras se mantiene despierto, su lugar "ha de ser tal que permita el correr del tiempo sucesivo, que empuje a la conciencia a generarlo por un movimiento intermitente". ${ }^{67}$ Con todo, este esfuerzo por comportarse intencionalmente está limitado por la contratendencia del yo a fundirse en la inmediatez de la psique; por lo mismo, nunca hay para el sujeto zambraniano conciencia plena:

Es así la vigilia un equilibrio que amenaza perderse en cada instante, sostenido por la tensión y el esfuerzo del sujeto solicitado contemporáneamente por las dos zonas en que la claridad escinde su ser, el ser que tiene a su cargo. En ella el sujeto ejerce su función primaria de separar y oponer el mundo de los objetos —zona de claridad consciente- y el mundo que queda oculto, el mundo subjetivo. Y paradójicamente, cuando la claridad que arroja la conciencia sobre lo real se acerca más a la transparencia, a la diafanidad, la realidad parece representársele más por sí misma, con entera independencia, como objeto. El sujeto entonces se libera temporalmente de la adhesión y del peso de lo subjetivo, del mundo en sombra. Mas pasado un cierto tiempo se le agudiza el sentir de su diferencia con ello; lo ve cuanto más objeto más extraño, más opaco e incognoscible. Es el dintel del conocimiento, su drama. ${ }^{68}$

Ocurre con el sujeto en vigilia que, si intenta sostener la atención frente a un objeto temporal sin dejarlo escapar o difuminarse del campo del tiempo por la puerta trasera de la retención, se compromete en un trabajo que excede sus fuerzas, de lo cual derivan dos efectos: $a$ ) el enrarecimiento de la vivencia de dicho objeto, artificialmente sostenida en el presente, una vivencia que se desnaturaliza porque el yo trata

${ }^{66}$ Loc. cit.

${ }^{67}$ Ibid., p. 109.

${ }^{68}$ Ibid., p. 40. 
de que no se convierta en sedimento, de que no "caiga" en la psique; b) el enrarecimiento del sujeto mismo respecto de su sustrato anímico, una distorsión de su estructura integral motivada por la sobresaturación anómala del polo intencionado. Estos dos efectos pueden detallarse como sigue.

En el caso del objeto "sobreatendido", la saturación anómala de la conciencia temporal se explica por violación de la regla fenomenológica de constitución de los contenidos noemáticos. En palabras de Blumenberg:

Cada cogito tiene su cogitatum, está relacionado con él en el modo de la intencionalidad en tanto relacionado con la unidad de la multiplicidad de sus datos, afecciones, impresiones originarias. El cogitatum regula el proceder del cogito según sus requisitos inmanentes de sentido, en tanto objeto que pertenece a un tipo determinado y exclusivo de aprehensibilidad. Precisamente por eso es que acto y objeto, noesis y noema son correlativos a priori. Pero el sentido del objeto no solo regula el procedimiento del acto de conciencia, sino también el "tramo" de conciencia del que se sirve para su constitución y que "llena" mediante una simetría coherente de retención y protención. El cogitatum es la regla que define qué se le presenta como dado a la conciencia, qué puede ser abarcado en su presente, simplemente porque "defiende" su requisito de sentido contra la corriente permanente de impresiones originarias frescas que “expelen" hacia el ya no, es decir, que lo mantiene en el recién todavía, y no deja que lo expelan de allí. ${ }^{69}$

De acuerdo con esto, "un nuevo cogitatum [...] implica nuevos requisitos de sentido de la relación entre objeto y acto, entre noema y noesis. Pero eso forzosamente implica que la reflexión corte e interrumpa la retención a cuyo acto objetivo [...] se dirige". ${ }^{70}$ Así, una conciencia forzada a extender el horizonte retencional persistiría en una captación objetual que impediría la entrada de nuevos datos por el umbral impresional, y ese taponamiento inhibiría el proceso de sedimentación de los

${ }^{69}$ Descripción del ser humano, p. 132.

${ }^{70}$ Loc. cit. 
contenidos ya captados; el yo entonces deformaría el objeto en su afán por reconducirlo a la "entrada" de la conciencia.

En el otro caso, un sujeto que procediera de este modo con sus objetos estaría tratando en vano de rebasar las fronteras de su campo temporal y, con ello, de comportarse no como una "conciencia limitada fácticamente según la analogía del horizonte", ${ }^{71}$ sino como una susceptible de "retención ilimitada". ${ }^{22}$ Así las cosas, en su intento de prolongación retencional infinita la conciencia sobresaturada acabaría por fusionarse con el objeto "sobreatendido" y, en esa especie de arrobo, disolvería la distancia fenomenológica y alcanzaría insospechadamente la condición de la inmanencia psíquica, aun cuando en plena vigilia. Es justo por eso que María Zambrano advierte:

En la vigilia el sujeto está entre la zona de claridad y la de sombra: acechado por la una y un tanto ofuscado por la otra, participa en las dos sin anegarse en ninguna: emerge, sobresale como algo impar, amenazado, sí, mas que nunca podrá ser anulado. Por ello media y transmite, hace pasar claridad a oscuridad y a la inversa. Pero antes opone una a otra; distingue. Pues sin distinción la zona de claridad vendría a sumirse no en la oscuridad, como sucede cuando cae en el sueño, sino que conservando su claridad se cerraría el círculo mágico de la luz, como en el sueño se cierra el círculo mágico de la oscuridad. La vigilia total no sería vigilia sino una clase superior de sueño [...] Para mantenerse en la vigilia ha de mantener la oposición y sobre ella actuar mediando. Ha de contener la resistencia de la zona en sombra. ${ }^{73}$

Dicho de otra forma: si el sujeto insiste en postergar la escansión iterativa de la intencionalidad que le da su contextura a la vigilia, el nootiempo sucesivo muta en la continuidad de la duración, y la conciencia desvinculada de la psique — negada a comunicar al alma el residuo periódico de sus captaciones vivenciales - comienza, irónicamente, a comportarse como si estuviera dormida.

${ }^{71}$ Ibid., p. 133.

${ }^{72}$ Loc. cit.

${ }^{73}$ Los sueños y el tiempo, p. 39. 
Veamos por último las implicaciones del hecho de que la conciencia se interrumpa de vez en vez, de que la vigilia dé paso al sueño. Se trata también de una escansión, aunque ya no de los contenidos atendidos, sino del dispositivo que constituye los contenidos. Con todo, hay cierto isomorfismo entre las dos interrupciones: al dormir, la conciencia suspende un tramo de su actividad constitutiva de vivencias, suspensión que reproduce a gran escala la sucesión de actos discretos que forman la cadena atencional.

Para María Zambrano "el dormir no es solo función, sino estado: el otro estado de la vigilia, su sombra. Sombra que pudiera muy bien ser su tiniebla originaria". ${ }^{74}$ En virtud de ello, volver a la vigilia desde la matriz psíquica equivale a un comienzo abrupto de una nueva serie de actos de conciencia: "Entramos a la vigilia por el despertar, que es cosa de un instante. Irrumpimos en ella como si desde algún oscuro lugar alguien, algo, una mano desconocida nos hubiera hacia ella lanzado despegándonos, desprendiéndonos violentamente de un estado natural en el que quedaríamos sin ese impulso exterior". ${ }^{75}$ Como explica Blumenberg, despertar tiene algo de milagroso para un sujeto cuya conciencia, si bien no puede funcionar sin escansiones reiterativas del flujo impresional-retencional, al menos aspira a esa idealidad aunque sea en la forma de un sostenido permanecer en el tiempo sucesivo; una idealidad, digamos, insomne:

Emerjo del sueño como si yo nunca hubiese existido. Solo una dudosa minucia me impide ser este neófito de la existencia: mis recuerdos y los de los otros sobre mí. Hay circunstancias, entorno, cosas que no se avienen a hacer como si yo hubiera aparecido por primera vez entre ellas. Yo las conozco, ellas me conocen. Por tanto, tiene su sentido que los demás me saluden, como yo a ellos, cuando nos encontramos por la mañana o a lo largo del día. Para ello solo es necesario "formar parte" en el más lato de los sentidos, de ningún modo hay que tener una intimidad especial: para un ser como el hombre - que puede dormir tan profundamente que la conexión con su "vida anterior" no le parece evidentela situación normal del haber-estado-ya precisa de la existencia de testigos.

${ }^{74}$ Ibid., p. 55.

${ }^{75}$ Ibid., p. 56. 
No se trata sencillamente de un etcétera. Se vuelve en sí: esto es increíble. Cada despertar es una resurrección, porque todo está en contra de que la conciencia se haya abandonado a su interrupción: se define por ser aque1lo que no soporta las interrupciones. Lo que se muestra como patología del insomnio es más bien la normalidad victoriosa de la existencia como "cura" de sí. ${ }^{76}$

Con parecido estupor, Zambrano constata que el sujeto "abre los ojos y ya está aquí despierto, nacido. No regresa de la muerte, regresa de algo anterior a la vida completa, de una pre-vida donde no se puede valer, donde la realidad no se le presenta, donde solo se siente a sí mismo". ${ }^{77}$ Ahora bien, este violento volver en sí, que se repite periódicamente, según la alternancia del dormir y el estar despierto, que reintegra al sujeto a su actividad consciente de vigilia después de un lapso de hundimiento en el subsuelo de la psique, equivale cada vez a un nacimiento parcial, a un recomienzo de la vida despierta, lo cual pone en evidencia cuán frágil es la estructura de la ipseidad del sujeto zambraniano, pues en ella se dan dos continuidades imperfectas: la de la duración psíquica, ininterrumpida pero deficitaria por ser vivencialmente opaca, y la de la sucesión consciente, rica en contenidos pero sometida a desconexiones periódicas. Respecto de su vida, dice la autora que el hombre se mantiene

no habitándola por completo, no enseñoreándola por entero, enseñoreándola sí, para disponer de ella, para extraer de ella un asunto, un argumento, una continuidad en suma bien diferenciada de la continuidad vivida: tratando a su vida como un continuo del que se extrae una continuidad establecida, lograda a través de la discontinuidad y aun de la alteración temporal. ${ }^{78}$

Vivir de esta manera significa, entonces, poder comenzar de nuevo con cada despertar y, a la vez, ser capaz de suturar cada recomienzo "diurno" con cada abrupto final "nocturno". Estos comienzos, finales, cesuras y suturas le dan a la ipseidad del sujeto zambraniano su perfil particular.

${ }^{76}$ Hans Blumenberg, La posibilidad de comprenderse, 2002, Madrid, Síntesis, p. 142.

${ }^{77}$ Los sueños y el tiempo, p. 66.

${ }^{78}$ Ibid., p. 28. 
CITAM Derechos Reservados.

La reproducción total o parcial de este artículo se podrá hacer si el ITAM otorga la autorización previamente por escrito. 